\title{
MANUSIA DAN AGAMA DALAM KAJIAN KEISLAMAN
}

\author{
Abdul Mujib Ramadhan \\ Prodi Ilmu Hadis Fakultas Ushuluddin dan Adab \\ Universitas Islam Negeri Sultan Maulana Hasanuddin Banten \\ abdmujibr1312@gmail.com
}

\begin{abstract}
According to Omar Muhammad Al-Toumy Al-Syaibany Humans are the most noble creatures, man is a thinking creature, and humans are creatures that have 3 dimensions (body, mind, and soul), humans in their growth are built by heredity and the environment. While, Religion is a means of guaranteeing individual space and fostering peace of mind for its adherents. Humans and Religion are closely related, As in essence, they have the status of a social being in social relations, and it cannot be separated from a religious personality which comes from religion. For example, we can look at religious norms related to social norms.
\end{abstract}

Keywords; Human, Religion, Human and Religion Relations

\begin{abstract}
ABSTRAK
Menurut Omar Muhammad Al-Toumy Al-Syaibany Manusia adalah makhluk yang paling mulia, manusia adalah makhluk yang berfikir, dan manusia adalah makhluk yang memiliki 3 dimensi (badan,akal,dan ruh), manusia dalam pertumbuhannya dipengaruhi oleh factor
\end{abstract}


keturunan dan lingkungan. Sedangkan, Agama merupakan sarana yang menjamin kelapangan dada dalam individu dan menumbuhkan ketenangan hati para pemeluknya. Manusia dan Agama amatlah berkaitan, sebagaimana Hakikatnya berstatus makhluk social dalam hubungan kemasyarakatan, dan tak dapat dipisahkan dengan kepribadian yang religious bersumber dari agama. Contohnya dapat kita lihat dalam norma-norma agama yang berkaitan dengan norma social.

Kata kunci; Manusia,Agama,Keterkaitan Manusia dan Agama

\section{PENDAHULUAN}

Manusia dengan akalnya dapat melahirkan ilmu pengetahuan dan teknologi, tetapi akal saja tidak mampu menyelesaikan seluruh persoalan yang dihadapi manusia. Terkait dengan hal ini agama sangat berperan dalam mempertahankan manusia untuk tetap menjaganya sebagai manusia. Kebutuhan manusia terhadap agama mendorongnya untuk mencari agama yang sesuai dengan harapan-harapan rohaniahnya. Dengan agama manusia dituntun untuk dapat mengenal Tuhan dengan segala sifat-sifat-Nya. Maka dari itu Manusia dan Agama tidak dapat dipisahkan karena Agama adalah pedoman hidup manusia,pembentuk karakter yang baik bagi manusia.

\section{A. Pengertian Manusia.}

Manusia adalah mahluk yang paling mulia, manusia adalah mahluk yang berfikir, dan manusia adalah mahluk yang memiliki 3 dimensi (badan, akal, dan ruh), manusia dalam pertumbuhannya dipengaruhi faktor keturunan dan lingkungan.

Membicarakan tentang manusia dalam pandangan ilmu pengetahuan sangat bergantung metodologi yang digunakan dan terhadap filosofis yang mendasari.

Para penganut teori psikoanalisis menyebut manusia sebagai homo volens (makhluk berkeinginan). Menurut aliran ini, manusia adalah makhluk yang memiliki perilaku interaksi antara komponen biologis (id), psikologis (ego), dan social (superego). Di dalam diri manusia tedapat unsur animal (hewani), rasional (akali), dan moral (nilai). Para penganut teori behaviorisme menyebut manusia sebagai homo mehanibcus (manusia mesin). Behavior lahir sebagai reaksi terhadap introspeksionisme (aliran yang menganalisa jiwa manusia 
berdasarkan laporan subjektif dan psikoanalisis (aliran yang berbicara tentang alam bawa sadar yang tidak nampak). Behavior yang menganalisis prilaku yang Nampak saja. Menurut aliran ini segala tingkah laku manusia terbentuk sebagai hasil proses pembelajaran terhadap lingkungannya, tidak disebabkan aspek.

Para penganut teori kognitif menyebut manusia sebagai homo sapiens (manusia berpikir). Menurut aliran ini manusia tidak di pandang lagi sebagai makhluk yang bereaksi secara pasif pada lingkungannya, makhluk yang selalu berfikir. Penganut teori kognitif mengecam pendapat yang cenderung menganggap pikiran itu tidak nyata karena tampak tidak mempengaruhi peristiwa. Padahal berpikir, memutuskan, menyatakan, memahami, dan sebagainya adalah fakta kehidupan manusia.

\section{B. Pengertian Agama}

Agama merupakan sarana yang menjamin kelapangan dada dalam individu dan menumbuhkan ketenangan hati pemeluknya. Agama akan memelihara manusia dari penyimpangan, kesalahan dan menjauhkannya dari tingkah laku yang negatif. Bahkan agama akan membuat hati manusia menjadi jernih halus dan suci.
Disamping itu, agama juga merupakan benteng pertahanan bagi generasi muda muslim dalam menghadapi berbagai aliran sesat.

Agama juga mempunyai peranan penting dalam pembinaan akidah dan akhlak dan juga merupakan jalan untuk membina pribadi dan masyarakat yang individuindividunya terikat oleh rasa persaudaraan, cinta kasih dan tolong menolong.

Agama berasa dari bahasa sansekerta yaitu, dari kata "A" yang artinya tidak dan "GAMA" artinya kacau. Jadi, agama artinya tidak kacau. dengan kata lain, agama merupakan tuntunan hidup yang dapat membebaskan manusia dari kekacauan. Didunia baratter dapat suatu istilah umum untuk pengertian agama ini, yaitu: religi, religie, religion, yang berarti melakukan suatu perbuatan dengan penuh penderitaan atau mati-matian, perbuatan ini berupa usaha atau sejenis per ibadatan yang dilakukan secara berulang ulang.

Agama menurut Kamus Besar Bahasa Indonesia adalah system yang mengatur tata keimanan (kepercayaan) dan peribadatan kepada Tuhan Yang Maha kuasa serta tata kaidah yang berhubungan dengan pergaulan manusia dan manusia serta lingkungannya.

Istilah lain bagi agama ini yang berasal dari bahasa arab, yaitu addiin yang berarti: 
hukum, perhitungan, kerajaan, kekuasaan, tuntutan, keputusan dan pembalasan. Kesemuanya itu memberikan gambaran bahwa "addiin" merupakan pengabdian dan penyerahan, mutlak dari seorang hamba kepada Tuhan penciptanya dengan upacara dan tingkah laku tertentu, sebagai manifestasi ketaatan tersebut (Moh.Syafaat, 1965).

\section{Manusia Menurut Agama Islam}

Yang dimaksud disini, manusia secara umum diciptakan dari segumpul darah dengan jenis dan ras yang berbeda-beda tapi mereka mempunyai proses penciptaan yang sama, hal ini menunjukkan bahwa Allah mengistimewakan manusia, agar mereka ingat dan menyadari bahwa Dia telah memberikan kemulian, melindungi peranan dan menjunjung tinggi kedudukan mereka diantara makhluk yang lain.

Meminjam istilah Dr. Ali Shariati, seorang intelektual Muslim, yang mengatakan bahwa: Manusia adalah makhluk dua dimensi yang membutuhkan penyelarasan kebutuhan akan kepentingan dunia dan akhirat. Oleh sebab itu, manusia harus memiliki konsep duniawi atau kepekaan emosi serta intelegensi yang baik dan penting.

Manusia adalah makhluk ciptaan Allah memiliki potensi untuk beriman (kepada
Allah), dengan mempergunakan akalnya mampu memahami dan mengamalkan wahyu serta mengamati gejala-gejala alam, bertanggung jawab atas segala perbuatannya dan berakhlak (N.A Rasyid, 1983:19).

Dalam Al-Quran manusia dipanggil dengan beberapa istilah, antara lain al-insaan, alnaas, alabd, dan bani adam dan sebagainya. Al-insaan berarti suka, senang, jinak, ramah, atau makhluk yang sering lupa. Alnaas berarti manusia (jama'). Al-abd berarti manusia sebagai hamba Allah. Bani adam berarti anak-anak Adam karena berasal dari keturunan nabi Adam.

Namun dalam Al-Quran dan Al-Sunnah disebutkan bahwa manusia adalah makhluk yang paling mulia dan memiliki berbagai potensi serta memperoleh petunjuk kebenaran dalam menjalani kehidupan di dunia dan akhirat.

Allah selaku pencipta alam semesta dan manusia telah memberikan informasi lewat wahyu Al-quran dan realita faktual yang tampak pada diri manusia. Informasi itu diberi- Nya melalui ayat-ayat tersebar tidak bertumpuk pada satu ayat atau satu surat. Hal ini dilakukan-Nya agar manusia berusaha mencari, meneliti, memikirkan, dan menganalisanya. Tidak menerima mentah demikian saja. Untuk mampu memutuskannya, diperlukan suatu peneliti 
Alquran dan sunnah rasul secara analitis dan mendalam. Kemudian dilanjutkan dengan melakukan penelitian laboratorium sebagai perbandingan, untuk merumuskan mana yang benar bersumber dari konsep awal dari Allah dan mana yang telah mendapat pengaruh lingkungan.

Pada dasarnya manusia adalah makhluk yg dibekali ruh dan jasmani (yg berasal dari tanah), dan dilengkapi potensi akal, hati dan jasad yg merupakan suatu kelebihan yg Allah berikan dibanding makhluk lain. Karenanya Islam mengatur seluruh hidup manusia dan memandang manusia dari berbagai dimensi secara komprehensif. Manusia selain diberi kebebasan, juga diberi tanggung jawab sebagai hamba dan khalifah.

Sebagai makhluk, manusia diciptakan untuk melakukan berbagai aktifitas salah satunya aktifitas kehalifahan yang harus bermuara dalam bentuk pengabdian kepada Allah, dengan demikian manusia adalah makhluk yang bercorak theosentris, bukan bercorak anthroposentris atau homosentris tetapi bercorak homo islamicus.

Manusia diciptakan oleh Allah Swt,antara musayyar dan mukhayyar. Mukhayyar adalah kebebasan manusia dalam memilih dan tidak ada kehendak Allah Swt di dalamnya dialah yang menciptakan perbuatannya sendiri dan mengatur urusannya. Hidup menurutnya berdasarkan sebab akibat. Musayyar adalah manusia yang digerakkan dan dikendalikan seperti robot tidak ada kehendak dalam perbuatannya. Dalam hal ini manusia seperti daun yang tertiup angin. Dalam konteks tauhid permasalahan mukhayyar dan musayyar adalah sebuah permasalahan yang berkaitan keimanan terhadap qadha dan qadar,karena ini menjadi sangat penting disaat terjadinya perbedaan tentang hak pilih. Apakah manusia yang berbuat ataukah ada campur tangan Allah dalam perlara tersebut.

Untuk melihat keterkaitan antara manusia dengan agama, dapat ditelusuri dari beberapa hal, di antaranya kodrat manusia beragama, gambaran manusia beragama, dan kebutuhan manusia akan agama.

\section{Kodrat Manusia Beragama}

Untuk mengetahui kodrat manusia beragama ini dapat dilihat pada beberapa fenomena berikut:

a. Tentang doa keselamatan.

Setiap orang pasti ingin mendapatkan keselamatan. Ia merasa dirinya selalu terancam. Makin serius ancamannya, doanya akan makin serius pula. Ia merasa kecil hidup di jagat raya ini seperti perahu kecil yang terapung di samudra yang amat luas. Karena ancaman tersebut ia ingin 
berpegangan dan menyandarkan diri kepada sesuatu yang ia anggap sebagai yang Maha Ghaib dan Maha Kuasa.

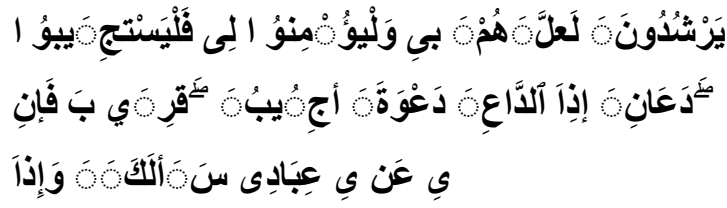

Artinya : Dan apabila hamba-hamba-Ku bertanya kepadamu tentang Aku, maka (jawablah), bahwasanya Aku adalah dekat. Aku mengabulkan permohonan orang yang berdoa apabila ia memohon kepada-Ku, maka hendaklah mereka itu memenuhi (segala perintah-Ku) dan hendaklah mereka beriman kepada-Ku, agar mereka selalu berada dalam kebenaran.

(Q.S Al-Baqarah: 186)

b. Tentang kebahagiaan abadi.

Setiap orang ingin mendapatkan kebahagiaan. Kebahagiaan yang ia harapkan bukanlah kebahagiaan yang sementara tetapi kebahagiaan abadi. Anehnya tidak setiap orang mendapatkan kebahagiaan abadi seperti yang ia harapkan.

c. Memerhatikan tubuh kita sendiri.

Apabila kita merenungkan dan memperhatikan tubuh kita sendiri sebagai manusia dengan kerangka dan susunan badan yang indah dan serasi dengan indra hati dan otak yang cerdas untuk menanggapi segala sesuatu di kanan kiri kita, akan sadar bahwa kita bukan ciptaan manusia, tetapi ciptaan Sang Maha Pencipta, Zat Yang Maha Ghaib dan Maha kuasa.

\section{Gambaran Manusia Beragama}

(Ekspresi Religius)

Gambaran pokok manusia beragama adalah penyerahan diri. Ia menyerahkan diri kepada sesuatu yang Maha Ghaib lagi Maha Agung. Ia tunduk lagi patuh dengan rasa hormat dan khidmat. Ia berdo'a, bersembahyang, dan berpuasa sebagai hubungan vertikal (hablun minallah) dan ia juga berbuat segala sesuatu kebaikan untuk kepentingan sesama umat manusia (hablun minannas), karena ia percaya bahwa semua itu diperintahkan oleh Zat Yang Maha Ghaib serta Zat Yang Maha Pemurah. Penyerahan diri itu oleh manusia yang beragama tidak merasa dipaksa oleh sesuatu kekuatan yang ia tidak dapat mengalahkan.

Penyerahan diri itu dirasakan sebagai pengangkatan terhadap dirinya sendiri karena dengan itu ia akan mendapat keselamatan dan kebahagiaan yang abadi. Penyerahan diri itu dilakukan dengan perasaan hormat dan khidmat dengan iman dan kepercayaan dengan pengertian di luar 
jangkauan manusia (metarasional). Penyerahan diri manusia itu bersifat bebas dan merdeka. Dengan rasa kesadaran dan kemerdekaan ia memeluk agama dan menjalankan peraturan- peraturan yang ia anggap dari Zat Yang Maha Ghaib itu.

\section{Kebutuhan Manusia akan Agama}

Kefitrahan agama bagi manusia menunjukkan bahwa manusia tidak dapat melepaskan diri dari agama, karena agama merupakan kebutuhan fitrah manusia. Selama manusia memiliki perasaan takut dan cemas, selama itu pula manusia membutuhkan agama. Kebutuhan manusia akan agama tidak dapat digantikan dengan kemampuan ilmu pengetahuan dan teknologi yang juga dapat memenuhi kebutuhan manusia dalam aspek material.

Kebutuhan manusia akan materi tidak dapat menggantikan peran agama dalam kehidupan manusia. Masyarakat Barat yang telah mencapai kemajuan material ternyata masih belum mampu memenuhi kebutuhan spiritualnya.

Manusia dengan akalnya dapat melahirkan ilmu pengetahuan dan teknologi, tetapi akal saja tidak mampu menyelesaikan seluruh persoalan yang dihadapi manusia. Terkait dengan hal ini agama sangat berperan dalam mempertahankan manusia untuk tetap menjaganya sebagai manusia. Kebutuhan manusia terhadap agama mendorongnya untuk mencari agama yang sesuai dengan harapan-harapan rohaniahnya. Dengan agama manusia dituntun untuk dapat mengenal Tuhan dengan segala sifat-sifat-Nya. ${ }^{1}$

Adapun keterikatan Manusia dan Agama tidak memaksakan untuk memeluk agama tertentu karena semuanya tergantung kepada kehendak Allah SWT, seperti Yang tertera dal firman

Allah taa'la.

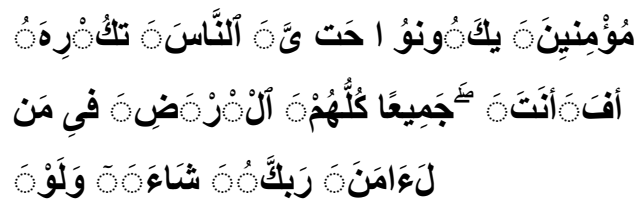

Artinya : Dan jikalau Tuhanmu menghendaki, tentulah beriman semua orang yang di muka bumi seluruhnya. Maka apakah kamu (hendak) memaksa manusia supaya mereka menjadi orang-orang yang beriman semuanya?. (Q.S Yunus:17)

Al-Zamaskhsyarî menegaskan bahwa persoalan keimanan adalah persoalan pilihan pribadimanusia, dan tidak boleh ada unsur paksaan. Upaya pemaksaan untuk memilih atau beragamabertentangan dengan sunnah Allah yang tercakup dalam surah Yûnus di atas.17 Setelah turun ayat di

\footnotetext{
${ }^{1}$ https://kompasiana.com
} 
atas Rasul SAW. mengatakan: "saudarasaudaramu itu memiliki pilihan,jika anakanak dan saudaramu itu memilih kamu, maka mereka bagian daripadamu(seagama denganmu). Jika anak-anak dan saudaramu itu memilih yang belum masuk Islamitu, maka mereka bagian dari yang belum masuk Islam itu". ${ }^{2}$

\section{Bagaimana Manusia Tanpa Agama}

Terserah agama apapun yang dianut, tetapi agama telah menjadi sumber inspirasi bagi manusia menemukan cara terbaik hidup aman, sentosa dan sejahtera. Dan semua agama mengajarkan dan menanamkan nilai-nilai kebaikan dan martabat hidup yang lebih mulia.

Agama mengajarkan manusia tentang keterbatasan dan ketidakberbatasan. Agama mengajarkan kebebasan itu bersyarat. Kebebasan mutlak adalah rimba raya. Untuk menjadi dan memiliki kebebasan total, maka yang diperlukan bukanlah dengan diri menjadi bebas berbuat apa saja. Manusia bisa memiliki kebebasan, hanya bisa ia raih dengan terlebih dulu membebaskan dan memerdekan orang lain, sesamanya.

Agama mengajarkan agar manusia mengolah daya pikirnya, supaya dapat

2 Misrah, KEBEBASAN BERAGAMA DALAM PERSPEKTIF HADIS,(Sumatera utara)Jurnal MIQOT Vol. XXXIV NO.2,Desember 2010.hal.183 menelaah rasa (hati-spiritualitas). Fungsi akal-pikir sejatinya adalah 'menerjemahkan` petunjuk-petunjuk yang diberikan Tuhan via hatinya, rasa-nya.

Karena itu, melalui agama, manusia kemudian dapat mengerti, di atas langit masih ada lagi langit. Agama juga mengajarkan terbatasnya akar pikir manusia. Karena itu, manusia perlu bersyukur agar daya pikirnya menjadi tak berbatas. Rasa diri yang tak pernah bersyukur, menjadikan manusia selalu serba ngotot dengan kemampuan akalpikirnya. Tindakan ngotot pada gilirannya menyebabkan otak mumet, buntu dan tak ada damai-damainya.

Akar dari hati adalah menghayati. Akar dari daya pikir adalah memahami penghayatan, dan menjelaskannya dalam bahasa-bahasa yang mudah dicerna semua orang. Daya pikir yang lepas dari akar hati, maka ia takkan mampu memahami. Daya pikir yang lepas dari hati, menyebabkan ia selalu terjebak di dalam alam perdebatan yang kunjung ada ujung pangkalnya. ${ }^{3}$

Maka dari itu Agama hadir untuk dijadikan Pedoman dalam kehidupan.

1.agama menghidupkan nilai luhur moralitas. Agama amat mendukung nilai

\footnotetext{
${ }^{3}$ http://kompasiana.com
} 
luhur yang menyeru kepada prinsip kebaikan, seperti keadilan, kejujuran, toleransi, dan tolongmenolong. Bila tanpa agama, prinsip kebaikan akan hilang, manusia tidak lagi memiliki tasa toleransi dan tolong menolong.

2.agama memberi kekuatan dalam menanggung penderitaan hidup. Agama menghidupkan kekuatan dalam diri manusia untuk mampu menghadapi sebagai penderitaan hidup dan berperan sebagai benteng kokoh yang melindunginya dari serangan keputusasaan dan hilangnya harapan. Tanpa agama manusia dapat dengan mudahnya putus asa, yang bisa berujung mengakhiri hidup tanpa berpikir lebih jauh.

3.agama menjadi pegangan dan pedoman hidup. Al-qur'an merupakan pedoman hidup yang tidak pernah berubah setiap zaman. Meskipun terdapat berbagai perbedaan tafsiran dalam memahaminya, namun tidak pernah ada perubahan dalam kitab suci yang diyakini kebenarannya tersebut. Jika tidak ada pegangan, makan hidup seorang manusia dapat terombangambing tanpa arahan yang jelas. ${ }^{4}$

\section{KESIMPULAN}

Manusia dengan akalnya dapat melahirkan ilmu pengetahuan dan teknologi, tetapi akal saja tidak mampu menyelesaikan seluruh persoalan yang dihadapi manusia. Terkait dengan hal ini agama sangat berperan dalam mempertahankan manusia untuk tetap menjaganya sebagai manusia

Agama mengajarkan manusia tentang keterbatasan dan ketidakberbatasan. Agama mengajarkan kebebasan itu bersyarat. Kebebasan mutlak adalah rimba raya. Untuk menjadi dan memiliki kebebasan total, maka yang diperlukan bukanlah dengan diri menjadi bebas berbuat apa saja. Manusia bisa memiliki kebebasan, hanya bisa ia raih dengan terlebih dulu membebaskan dan memerdekan orang lain, sesamanya. Agama mengajarkan agar manusia mengolah daya pikirnya, supaya dapat menelaah rasa (hati-spiritualitas). Fungsi akal-pikir sejatinya adalah 'menerjemahkan` petunjuk-petunjuk yang diberikan Tuhan via hatinya, rasanya.

\section{DAFTAR PUSTAKA}

Al-Qur' an Cordoba Special For

Muslimah.Bandung:PT.Cordoba Internasional Indonesia.

Misrah, KEBEBASAN BERAGAMA DALAM

PERSPEKTIF HADIS, (Medan:IAIN

Sumatera Utara)Jurnal MIQOT Vol. XXXIV

NO.2, Desember 2010.

https://kompasiana.com

\footnotetext{
${ }^{4}$ https://brainly.co.id
} 
https://brainly.co.id 